Article

\title{
Community Participation and Preferences Regarding Conservation and Development Policies in China's Giant Panda Nature Reserves
}

\author{
Ben Ma and Yali Wen * \\ School of Economics and Management, Beijing Forestry University, Beijing 100083, China \\ * Correspondence: wenyali@bjfu.edu.cn
}

Received: 29 June 2019; Accepted: 2 September 2019; Published: 5 September 2019

check for updates

\begin{abstract}
Community participation in conservation activities is an important mechanism to coordinate the conflicts between conservation and local development. Hence, it is necessary to understand farmers' preferences for different conservation and development policies. By surveying households residing inside and outside the four giant panda nature reserves in the Qinling Mountains, China, in 2018, this study uses a choice experiment model to evaluate participation willingness and stated preferences regarding the establishment of national parks (NPs), ecotourism development, ecological public welfare forest compensation, and provision of ecological jobs. Our results suggest that these conservation and development policies all have a positive impact on community participation in conservation. Among the different conservation and development policies, farmers seem to prefer the government developing ecotourism most, followed by providing ecological jobs, establishing NPs, and finally the compensation amount and period of ecological public welfare forests. Moreover, farmers with different characteristics have different preferences regarding conservation and development policies. Age, education level, whether the respondent is a village cadre, family forestland area, family income, and whether the respondent lives in a nature reserve are relevant socio-economic characteristics of the affected farmers.
\end{abstract}

Keywords: choice model; compensation; ecotourism; farmers' preference; Giant Panda National Park

\section{Introduction}

Globally, policymakers tout community participation as an effective tool in the coordination of biodiversity conservation and community development [1,2]. The establishment of protected areas (PAs) is one of the most effective ways to protect biodiversity [3,4]. However, biodiversity hotspots tend to be located in rural areas, where conservation activities may hinder local development due to restricted access to natural resources [5,6]. Especially in China, most PAs are located in the central and western regions, which are less economically developed than other regions within China [7]. Of the 592 national poverty-stricken counties, $496(84 \%)$ are located in mountainous areas where nature reserves (NRs) were established [8].

Most existing studies focus on the livelihoods and ecological impacts of conservation and development policies $[9,10]$. Some studies have shown that the establishment of PAs has no significant impact on community livelihoods [11,12]. However, most studies have shown that the establishment of PAs has increased community poverty [13-17]. The positive impact of the establishment of PAs on the community has also increasingly been confirmed $[18,19]$. At the same time, the impact of ecotourism in the PAs on the community is also a hot topic of current research. The positive livelihoods of ecotourism are realized in many developing countries [20-22]. Ferraro and Hanauer [23] found that among the positive effects of PAs on poverty reduction, ecotourism contributed two-thirds. However, ecotourism 
is not a panacea, while many success stories exist, there are also failures [24-27]. Community-based ecotourism was found to increase income inequality in Colombia and Qinling, China [28,29].

Payments for ecosystem services (PES) is a popular tool to halt biodiversity loss and enhance local livelihoods. Specifically, PES are incentives offered to farmers or landowners in exchange for managing their land to provide some sort of ecological service. These initiatives have been widely implemented at the community, regional, or country level [30]. PES is often used as an auxiliary tool to support the enforcement of the preexisting system of PAs in developing countries [31]. China was an early adopter of PES, introducing the sloping-land conversion program in 2002 and the natural forest conservation program in 2000, which have increased forest cover and some ecosystem services [32,33]. However, these PES programs in China are implemented via a top-down approach, rely heavily on state financing, and insufficiently consider local interests [34]. Moreover, tradeoffs between environmental and social outcomes are often found in PES programs [35].

Most biodiversity conservation policies are prevalent in PAs and put forward in a top-down manner, which is led by the central government in policy planning, arrangement, organization, and implementation [36]. Although this pattern can achieve quick and effective conservation impact, it ignores some stakeholders' benefits (e.g., community, local government). The establishment of national parks (NPs) in China has followed such a top-down mode. Initially set up in November 2013, it was clearly stated that the pilot establishment of the NP system would be basically completed by 2020 [37]. In October 2018, the unveiling ceremony of the Giant Panda NP administration was held in Chengdu, Sichuan, marking the beginning of a comprehensive phase of the pilot project of the Giant Panda NP. The project is aimed to summarize an effective model and make the establishment of the NP a successful experience [38]. Despite its high implementation efficiency, the top-down approach gives limited consideration to local interests [37]. The local community is the direct target of the conservation policy, and community members are important participants in biodiversity conservation. Hence, their response to the policy is related to the efficiency of its implementation. To this end, in the process of policy implementation, it is necessary to pay attention to the will of the community. Our study optimizes the conservation policy from the perspective of the community's participation and preferences for biodiversity conservation policies and then optimizes the policy implementation process.

A majority of the literature focuses on the impact of conservation and development policies [9,12,28]. At the community level, this mainly comprises an impact assessment on the community's livelihoods. In the evaluation of the effectiveness of conservation and development policies, existing research has achieved remarkable results [9,34]. However, few studies are analyzed from the perspective of community participation and preferences. Moreover, the assessment of conservation and development policies is mostly separate, while, in reality, their implementations often interact and work together [9].

Existing research has attempted to optimize conservation and development policies from a stakeholder preference perspective. Pienaar et al. [39] applied a choice experiment framework to value conservation-contingent development programs and found that solar power projects, job training, cash compensation, and conservation jobs can incentivize households to engage in anti-poaching enforcement, re-vegetation of wildlife habitat, and wildlife monitoring. Lee and Du Preez [40] used a choice experiment model to analyze tourists' preferences of rhinoceros conservation management policies in South Africa's private ecotourism hunting areas. They considered the choice experiment technique a promising instrument to inform the design of rhinoceros management and conservation policies. Existing research that uses the choice experiment model to optimize and improve policy from the perspective of stakeholders' stated preferences has achieved good results, which provides a good foundation and reference for the current research.

To this end, this study focuses on the implementation process of conservation and development policies from the perspective of community preferences and explores the latter's willingness to participate. This is helpful to develop a community-based, participatory approach to park management, which explicitly addresses the criticisms to the top-down approach ignoring community participation [37]. Our study contributes to the literature by exploring community preferences for 
different conservation and development policies from the perspective of local households. The rest of this paper is organized as follows. Section 2 presents the experimental design and variables selection of this study and describes the design of attributes and levels as well as the questionnaire. Next, Section 3 describes the data collection and research method. Section 4 presents and describes our results. Finally, Section 5 discusses the main conclusions and policy implications, while highlighting the limitations of this study.

\section{Experimental Design and Variables Selection}

\subsection{Attributes and Levels}

The core of an experimental design is the determination of the attributes and levels. Given the purpose of this study of understanding the participation and preferences of communities for conservation and development policies, the specific attributes and corresponding levels are shown below.

The questionnaire survey was conducted from July to October 2018 in four NRs in Qinling, Shaanxi. During the investigation, the Giant Panda NP was still in the pilot exploration stage, and the management institutions and boundaries were not clearly defined. However, after the establishment of the NP, it became clear that the existing policies could not meet the needs of conservation and development. Therefore, based on existing conservation and development policies, this study designed community participation programs to understand the communities' needs for conservation and development policies and provide a decision-making reference for the government to implement relevant policies.

The design process of the scheme is as follows: Firstly, based on a study of relevant literature and documents on regional policies and NR management, we conducted interviews on issues such as NR management policy, forest compensation programs, participation in ecological jobs, and implementation of ecotourism to understand the needs and opinions of different stakeholders (communities, experts, managers) concerning the current policy. Next, experts and NR managers in the field of natural sciences and social sciences were consulted on the rationality and operability of an initial selection of relevant attributes and levels, and these were continuously improved. This approach finally determined the following attribute variables of conservation and development policies: establishment of NP, ecotourism development, compensation period for public welfare forests, provision of ecological posts, and compensation for public welfare forests.

Before the establishment of the Giant Panda NP, the conservation of the giant panda species and their habitats was dominated by NRs. In the Qinling area, 16 NRs were established to protect giant pandas (Ailuropoda melanoleuca). However, the NR-based conservation system cannot solve the problem of the fragmentation of the giant panda habitat. For this reason, the government has established a pilot project for the Giant Panda NP across Sichuan, Shaanxi, and Gansu provinces with a total area of 27,134 square kilometers. The conservation area has been further expanded, and many communities outside the NRs are about to be included in the PA. In order to understand the communities' attitudes toward the establishment of the NP, the program chose to maintain conservation status quo and incorporating the communities into the NP management as two levels of the attribute variable.

Ecotourism is an important means of coordinating conservation and development. Ecotourism attribute variables is divided into two levels: maintaining the status quo and increasing the development of scenic spots. Many community collective forestlands are included in the PAs. Most forestlands are classified into national or provincial ecological public welfare forests (Ecological public welfare forest refers to the protective forest that is located in extremely fragile ecological places, playing an important role in national ecological security, biodiversity conservation, and economic and social sustainable development. Its main operation objectives include providing forest ecological and social services). The compensation standard for state-level public welfare forests is 15 yuan ( $\$ 1=$ RMB 6.62 (Source: China Bank exchange rate, 2018 average)) per mu (1 ha =15 mu.) annually, which means 
households whose contracted forestland are included in stated-level public welfare forests can receive 15 yuan per mu compensation annually. The average standard of provincial-level ecological forest compensation is five yuan per mu annually. At present, there is no clear compensation period for ecological public welfare forests. The compensation amount is transferred to the farmers every year. Most community residents hoped for the specification of a clear public welfare forest compensation period, after which they would be compensated according to the new conservation and development status. The compensation cycle times preferred by different community residents were one year, five years, and ten years. Therefore, the levels of compensation for the ecological public welfare forest are classified as 0, 1-10 yuan/mu/year, 11-20 yuan/mu/year, and 21-30 yuan/mu/year. In the data analysis process, each interval is treated as its corresponding average, for example, about 5 yuan/mu/year for the interval of 1-10 yuan/mu/year. The levels of the compensation period attribute of ecological public welfare forest are divided into one year, five years, 10 years, and 15 years.

Ecological jobs are an important means for communities to participate in biodiversity conservation and are important measures for community-based natural resource management. By participating in forest patrols (e.g., becoming a forester), the community members can not only improve their livelihoods, but also alleviate the work pressure of management personnel. The eco-post setting is the focus of community participation in the Giant Panda NP master plan. The levels of ecological job attributes are divided into not providing ecological positions and providing ecological positions.

\subsection{Questionnaire Design}

After determining the attributes and levels of the experimental design, it is necessary to design a household survey questionnaire accordingly. Ideally, the full factor design must not only satisfy the orthogonality (i.e., the alternatives are independent), but also the balance (i.e., each level of the attribute appears the same number of times in the column) requirement. The full factorial design can calculate the main effects of the attributes and also, analyze the interaction effects between different attributes. However, the full factor design needs to consider the combination of all attributes and their levels, which would be a total of $128(2 \times 2 \times 4 \times 2 \times 4)$ choices of community participation in the conservation and development policy portfolio. Households need to compare $C_{2}^{128}$ policy combinations, which is not feasible in reality. Therefore, a partial factor design is needed to reduce the number of choices. This study is based on Stata 15 using the D-efficiency measure approach for the partial factor design. The main principles are based on the following.

The conditional logit probability $P_{n j}$, representing the probability that farmer $n$ chooses the $j$-th policy, can be calculated as follows:

$$
P_{n j}=\frac{\exp \left(x_{n j}^{\prime} \beta\right)}{\sum_{j=1}^{J} \exp \left(x_{n j}^{\prime} \beta\right)}
$$

where parameter $\beta$ (i.e., farmers' preference for different attribute variables) must be estimated. Thus, the selection set scheme is constructed in order to estimate $\beta$ as accurately as possible. The accuracy of the estimation can be expressed by the variance-covariance matrix of the estimated coefficient $\beta$. Under the conditional logit model, the matrix is expressed as:

$$
\Omega=\left[\sum_{n=1}^{N} \sum_{j=1}^{J} z_{n j}^{\prime} P_{n j} z_{n j}\right]^{-1}
$$

where

$$
z_{n j}=x_{n j}-\sum_{j=1}^{J} x_{n j} P_{n j}
$$

Based on this, it can be observed that the expression is calculated using the estimated coefficients of the attribute parameters. In the process of designing the research experiment, the estimation coefficient of the attribute parameter cannot be observed in advance. Otherwise, there would be no need to design 
a survey plan. Nonetheless, the coefficient size of the attribute parameter can be estimated through preliminary investigation, failing which, it can still be input as 0 . Here, the estimated coefficient of the parameter is set as 0 to calculate the variance-covariance matrix. An efficient experimental design principle is to minimize the variance-covariance matrix by constructing the experimental design based on the estimated coefficients of a given attribute parameter. There are different efficiency measures for minimizing the matrix, the most common of which is the D-efficiency value, which is expressed as:

$$
\text { D-efficiency }=\left[|\Omega|^{1 / k}\right]^{-1}
$$

where, $k$ is the number of parameters in the model. The D-efficiency estimate is used to identify the experimental design that maximizes this efficiency value. This measure becomes a D-efficient design.

Omitting the no-choice option in the experimental design limits the participants' ability to make effective decisions because, under non-hypothetical conditions, if the option scheme is unattractive, the participants would postpone or reject the choice. Therefore, in this study, each selection experiment card consists of two different change options and a no selection option [41]. In general, respondents who are made to evaluate more than 20 cards would be fatigued [42], the number of cards must be reduced to increase consumer choice efficiency. The D-efficiency model was used to design a selection experiment.

Finally, a total of 16 selection sets were generated comprising 32 selections. Given that the respondents would have to evaluate more than 20 options, it would result in fatigue, and this affects selection efficiency. The command is divided into two sets of experimental programs, whereby the respondents only need to make choices among eight selection sets, which greatly improves selection efficiency while reducing respondent and investigator fatigue. One sample selection can be seen in Appendix A, Table A1. Specifically, the d-create command in Stata is used to select based on the modified Fedorov algorithm [43-45].

\section{Data and Method}

\subsection{Study Area}

For our research, we selected four NRs in the Qinling Mountains: Changqing, Huangguanshan, Foping, and Zhouzhi (Figure 1). The Qinling Mountains divide China into North and South areas, which are characterized by different climates. The Qinling Mountains are also a watershed between the Yellow River and the Yangtze River systems, making the area one of the most important for biodiversity conservation in China. There are 23 forestry NRs in the Qinling Mountains, and16 of them are giant panda protection areas (353,735 hectares), home to approximately 345 wild giant pandas in 2017 . However, the local economy of counties/cities in the Qinling Mountains heavily relies on agriculture and natural resources (e.g., timber and firewood harvesting, medicinal herbs) [46]. The socio-economic development in the area is far below the national average.

As shown in Table 1, the selected NRs are managed at either the national or provincial level and include different protected species (e.g., giant pandas and golden monkeys). Four counties within or near the selected reserves were selected for the study. Based on farmers' per capita net income, per capita GDP, and fiscal revenue, two of them are defined as national poverty counties [47]. Community participation in ecological positions has been observed in the survey area, but remains insufficient. Indeed, only a very small number of people in each village can obtain this type of jobs, despite the enthusiasm displayed by most farmers when interviewed. It is also worth noting that the local government has developed ecotourism based on Changqing, Huangguanshan, and Foping NRs. 


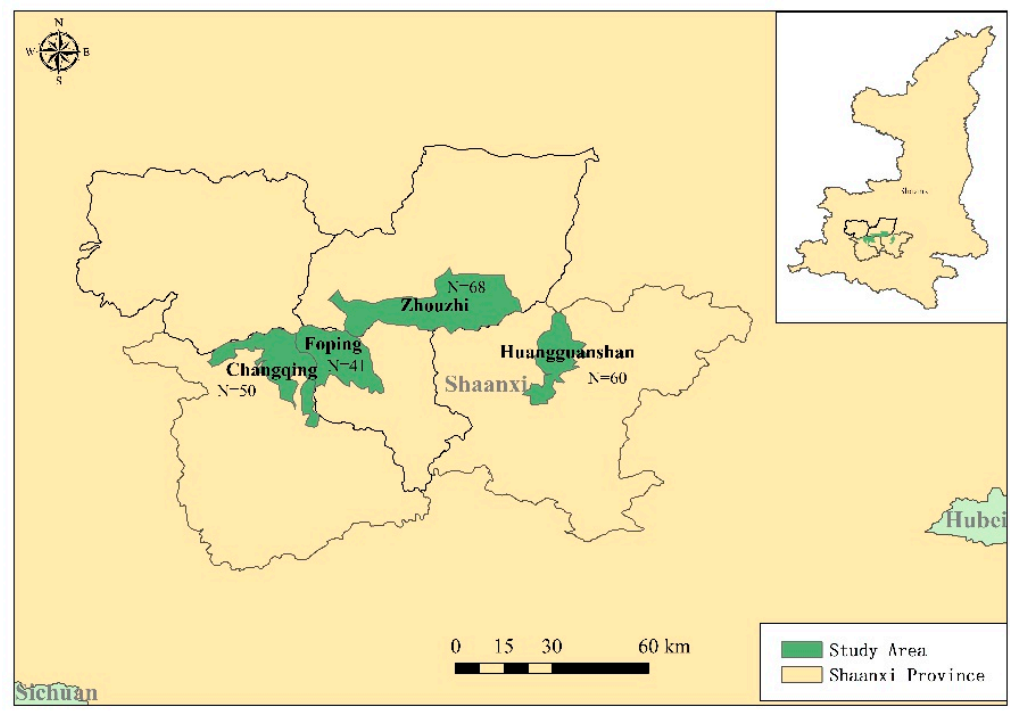

Figure 1. Study area.

Table 1. Description of selected nature reserves in Qinling, China.

\begin{tabular}{cccccc}
\hline Name & $\begin{array}{c}\text { Administrative } \\
\text { Region }\end{array}$ & Area (Hectare) & Level & Conservation Target & $\begin{array}{c}\text { Year } \\
\text { Established }\end{array}$ \\
\hline Changqing & Yang County * & 29,906 & National & $\begin{array}{c}\text { Giant pandas, torus, and } \\
\text { their habitats }\end{array}$ & 1994 \\
\hline Huangguanshan & Ningshan County * & 12,372 & Provincial & $\begin{array}{c}\text { Giant pandas and their } \\
\text { habitat }\end{array}$ \\
\hline Foping & Foping County & 29,240 & National & $\begin{array}{c}\text { Giant pandas, golden } \\
\text { monkeys and their } \\
\text { habitats }\end{array}$ \\
\hline Zhouzhi & Zhouzhi County & 56,393 & National & $\begin{array}{c}\text { Golden monkeys, other } \\
\text { wild animals, and their } \\
\text { habitats }\end{array}$ \\
\hline
\end{tabular}

Note: * indicates national poverty counties. Source: National Nature Reserve Directory (Ministry of Environmental Protection of the People's Republic of China, 2016) [48].

\subsection{Data Collection}

Survey data were collected from the surrounding communities of the four NRs from July-September 2018. In order to optimize the investigation plan for the choice experiment, a pretest was conducted in the area during August 2017, and feedback was collected to understand whether the attributes and levels of the design of the experimental program are consistent with reality. Specific interviewees included village cadres, village representatives, and management personnel. Interviews with the first two mainly serve to understand whether the community can distinguish between the various options and make choices. According to preliminary survey results, more than $80 \%$ of farmers can complete the choice of policy attributes with the help of investigators.

The research team adjusted and optimized the experimental plan based on the pre-survey results and officially launched the survey in 2018 among households that were randomly selected in each village. Our data collection team comprised 22 trained social researchers- 12 graduate students and 10 staff from the NRs-who have rich experience in conducting household surveys and have assisted us with other survey-based projects for nearly a decade. The survey objectives and questions were explained to them to minimize potential miscommunication when administering the questionnaire.

The head of the household was invited to participate in the survey, and questionnaires were completed face to face with the assistance of an on-site investigator and it took 45-60 min to complete. If the household head was absent, another adult family member was surveyed. The investigators were required to crosscheck the completed questionnaires with one another to eliminate invalid responses. In the end, a total of 260 choice experimental questionnaires were received. Excluding some 
respondents who could not understand the experimental content and refused to participate, a total of 219 valid questionnaires were obtained comprising 41 from Foping NR, 60 from Huangguanshan NR, 50 from Changqing NR, and 68 from Zhouzhi NR, of which 123 households were inside and 96 households were outside the NR. Definitions and statistical measurements of key variables are summarized in Table 2.

Table 2. Variables definitions and measurement.

\begin{tabular}{|c|c|c|c|c|}
\hline Variable & Variable Definition & Obs & Mean & Std.dev. \\
\hline Y & $\begin{array}{l}\text { Farmer's choice in each selection }(1=\text { choose this } \\
\text { conservation and development policy mix; } 0=\text { do } \\
\text { not choose })\end{array}$ & 3504 & 0.45 & 0.50 \\
\hline NP & $\begin{array}{l}\text { Establishment of NP }(1=\text { incorporated into NP; } 0=\text { status } \\
\text { quo) }\end{array}$ & 3504 & 0.50 & 0.50 \\
\hline ECOTOURISM & $\begin{array}{l}\text { Ecotourism development }(1=\text { increasing the development of } \\
\text { scenic spots; } 0 \text { = status quo) }\end{array}$ & 3504 & 0.50 & 0.50 \\
\hline YEAR & Conservation period of ecological welfare forests (years) & 3504 & 8.00 & 7.00 \\
\hline JOB & $\begin{array}{l}\text { Whether government will provide ecological jobs to farmers } \\
(1=\text { yes; } 0=\text { no })\end{array}$ & 3504 & 0.50 & 0.50 \\
\hline COMPENSATION & $\begin{array}{l}\text { Compensation for ecological welfare forests } \\
(0=0 \text { yuan/mu/year; } 5=1-10 \text { yuan } / \mathrm{mu} / \text { year; } \\
15=11-20 \text { yuan/mu/year; } 25=21-30 \text { yuan } / \mathrm{mu} / \text { year })\end{array}$ & 3504 & 12.50 & 12.50 \\
\hline AGE & Householder age (years) & 219 & 51.56 & 12.04 \\
\hline EDU & Householder education (years) & 219 & 6.81 & 3.50 \\
\hline VILLAGER & Whether householder is a village cadre $(1=$ yes; $0=$ no $)$ & 219 & 0.13 & 0.33 \\
\hline PA & Whether householder lives inside the NR $(1=$ yes; $0=$ no $)$ & 219 & 0.56 & 0.50 \\
\hline FORESTLAND & Household forestland area $(\mathrm{mu})$ & 219 & 78.11 & 121.68 \\
\hline INCOME & Household per capita income (yuan) & 219 & 10,575 & 13,764 \\
\hline
\end{tabular}

\subsection{Research Method}

The choice experimental model is a quantitative analysis method for processing preferences by setting a series of selections without displaying the preference data, which is a kind of stated preference method. Compared with revealed preference, in which the respondent can only observe the selection of an event that has already occurred in reality and cannot select a scenario that has not occurred but may occur in the future. By consulting the respondents' choices under different hypothetical scenarios, the choice experiment can help observe the respondents' preferences for possible scenarios. Based on the theory of stochastic utility, this method assumes economic rationality and utility maximization [49]. When indicating preferences, an individual is assumed to choose a set of choices that will bring the greatest benefit to the individual (i.e., the individual's choice is based on utility maximization). In turn, the utility of the selection set is based on the specific combination of attributes and schemes [50].

Based on Lancaster's theory of random utility [50], whether a farmer participates in a policy mix depends on the specific policy's attributes. It is assumed that the policy attributes are a random combination of the five attributes of the establishment of NP, compensation period, ecotourism development, ecological jobs, and ecological public welfare forest compensation, and their corresponding levels. Farmers make choices based on maximizing their own utility. Specifically, the total utility $U_{n i}$ of the $i$-th policy attribute combination for the $n$-th farmer can be expressed as:

$$
U_{n i}=V_{n i}+\varepsilon_{n i}
$$

where

$$
V_{n i}=\sum_{k=1}^{5} x_{i k}^{\prime} \beta
$$


$V_{n i}$ is the utility of the combination of observable attributes, $x_{i k}^{\prime}$ represents the $k$-th attribute of the attribute combination vector of the $i$-th policy, $\beta$ is a coefficient vector of the attribute parameter, and $\varepsilon_{n i}$ is a random error term representing the utility of the unobservable part.

The probability that a farmer chooses a scheme $i$ comprising a combination of policy attributes is:

$$
\begin{aligned}
P_{n i} & =\operatorname{Pr}\left(U_{n i}>U_{n j}\right) \forall j \neq i \\
& =\operatorname{Pr}\left(V_{n i}+\varepsilon_{n i}>V_{n j}+\varepsilon_{n j}\right) \forall j \neq i \\
& =\operatorname{Pr}\left(\varepsilon_{n j}-\varepsilon_{n i}<V_{n i}-V_{n j}\right) \forall j \neq i
\end{aligned}
$$

When analyzing the choice experimental model data, it is usually assumed that the random items are independent of each other and obey the independent and identically distributed (IID) type 1 extreme value distribution. According to McFadden [51], the selection probability of the farmers is:

$$
P_{n i}=\frac{\exp \left(\sigma_{n} V_{n i}\right)}{\sum_{j=1}^{J} \exp \left(\sigma_{n} V_{n i}\right)}
$$

The utility of this choice, $V_{n i}$, can be expressed as a specific linear parameter function:

$$
V_{n i}=x_{n i}^{\prime} \beta+z_{n}^{\prime} \gamma_{i}
$$

where $\sigma_{n}$ is a scale parameter, which is usually normalized to $0-1$, assuming $\varepsilon_{\mathrm{nj}}$ is homoscedastic, $x_{n i}^{\prime} \mathrm{s}$ an explanatory variable that varies with individual $n$ and scheme $i$, and $z_{n}^{\prime}$ is an explanatory variable that varies only with individual $n$. The conditional logit model is usually estimated using the asclogit (alternative-specific conditional logit) command in Stata. However, the conditional logit model assumes that farmers prefer homogeneity and random items are identical and independent. However, this may be biased by the independence of irrelevant choices [52], and the farmer homogeneity hypothesis differs from reality, with farmers' preferences being heterogeneous $[53,54]$. To this end, the mixed logit model is considered a more appropriate method to study the decision-making behavior of farmers with heterogeneous preferences. The mixed logit model can simulate any random utility model [55], which is especially effective when a respondent is required to go through multiple iterations [56]. The selection probability using a mixed logit model is:

$$
P_{n i}=\int \frac{\exp \left(x_{n i}^{\prime} \beta\right)}{\sum_{j=1}^{J} \exp \left(x_{n i}^{\prime} \beta\right)} f(\beta \mid \theta) d \beta
$$

where $f(\beta \mid \theta)$ is a density function of $\beta$. The mixed logit model allows all coefficients to differ across different farmers, implying that there is heterogeneity in farmers' preferences. Thus, this study uses a mixed logit model to analyze farmers' preferences for conservation and development policies. In Stata, this model is usually estimated using the maxlogit command for the maximum simulated likelihood [57].

In order to analyze the marginal value of different conservation and development policies, this study computes the point estimate of the non-price policy attribute unit change value (marginal value), which is termed Marginal Willingness to Accept (MWTA). This represents the marginal replacement rate of the price attribute versus other attributes [58] and is computed as follows:

$$
M W T A=-\frac{\beta_{n k}}{\beta_{n c}}
$$

where, $\beta_{n c}$ and $\beta_{n k}$ are the estimated coefficients of the ecological public welfare forest compensation and other conservation and development policy attributes, respectively. 


\section{Results and Discussion}

\subsection{Impact of Different Policies on Household Participation in Conservation}

As shown in Table 3, different conservation and development policy attributes can significantly increase farmers' willingness to participate in conservation. Specifically, the establishment of the Giant Panda NP can increase the probability of farmers' participation by $31.4 \%$. This indicates that farmers have a positive attitude towards the establishment of the Giant Panda NP. Although most farmers do not understand the concept and management system of the NP, the existing NR system emphasizes the species and its habitat protection. Strict conservation management ignores the interests of community participation and the community at large, although the communities' dependence on natural resources is decreasing with increased urbanization and non-agricultural employment opportunities [59,60]. However, the restrictions imposed by the construction of NRs on community development remain, protection has not brought about an improvement in community livelihoods. Therefore, the communities are dissatisfied with the current status of conservation management. The NP management system emphasizes the importance of community participation, and this is expected by the communities.

Improving the development status of ecotourism around the PA plays an important role in the communities' willingness to participate in conservation and development programs, and can increase its probability by $154 \%$. With climate change and improved living standards of urban residents, the demand for ecotourism in Qinling is growing vigorously. The poverty reduction and welfare enhancement effects brought about by ecotourism are significant and result in improvements in the living environment and transportation facilities, as well as increased non-agricultural employment opportunities. The effect of ecotourism on community livelihoods is obvious, although it may also have negative impacts such as environmental pollution and income inequality [29]. Therefore, ecotourism development is an important means of community-based natural resource management and an important mechanism to enhance community participation in conservation. During the interview process, the communities expressed that ecotourism development was their most urgent need. Most communities deem ecotourism activities to be more valuable than agroforestry production, and the enthusiasm for participating in ecotourism is very high. However, they are not satisfied with the current level of ecotourism development, mainly due to insufficient community participation, which fails to effectively attract tourists.

It is noteworthy that, after the establishment of the NP, the protected area will be further expanded. It is inevitable that the cultivated land and forestland closely related to the farmers' agroforestry production, and especially the community collective forestland, will be included in the conservation area. As an important part of the giant panda habitat, its use will be subject to strict restrictions including the collection of forest products, fuel wood, and wood, thereby making the formulation of ecological public welfare forest compensation programs crucial. Although the government has already developed a comprehensive compensation plan for ecological public welfare forests, the communities remain unsatisfied as the existing compensation scheme is top-down and the compensation amount varies each year. Moreover, there is no effective supervision mechanism at the village level, the communities passively accept the annual compensation amount, there is a lack of response and feedback mechanisms, and communities cannot depend on the compensation as a stable income channel. During the interview process, the community, and especially the farmers located in and around the PAs, expressed their dissatisfaction with the current compensation standards. Nonetheless, most shared that if the government provided ecological jobs or participated in ecotourism, the compensation would be lower. Additionally, while forestland resources located in and around NRs often have more important ecological and economic value and are, hence, more important to household livelihoods, the existing compensation standards are consistent across the region, and there is no increased compensation in important and biodiversity-rich areas. 
The regression results show that farmers prefer a compensation scheme with a long compensation period, indicating that the communities hope to obtain a stable source of income from the compensation of ecological public welfare forests. For each additional year of compensation, the probability of community participation programs increases by $2 \%$. The amount of compensation has a significant positive impact on community participation. For an additional one yuan/mu compensation for ecological public welfare forests, the probability of community participation in the policy program will increase by $8.21 \%$. Ecological jobs also have a significant positive impact on community participation in conservation, increasing its probability by $122 \%$. These jobs are an important mechanism for the communities to achieve sustainable development, especially among poor farmers. In fact, ecological posts form the platform for farmers to directly participate in the protection and earn direct non-agricultural incomes from ecological protection with low entry barriers.

Table 3. Mixed logit estimation results of farmer protection and development policy attribute preferences.

\begin{tabular}{|c|c|c|c|c|}
\hline \multirow{2}{*}{ Variable } & \multicolumn{2}{|c|}{ Mean } & \multicolumn{2}{|c|}{ SD } \\
\hline & Coefficient & Standard Error & Coefficient & Standard Error \\
\hline \multicolumn{5}{|l|}{ Attributes } \\
\hline NP & $0.314 *$ & 0.180 & $-0.969 * * *$ & 0.352 \\
\hline ECOTOURISM & $1.540^{* * *}$ & 0.334 & $3.971^{* * *}$ & 0.395 \\
\hline YEAR & $0.020 *$ & 0.011 & $0.050 * * *$ & 0.015 \\
\hline $\mathrm{JOB}$ & $1.218^{* * *}$ & 0.250 & $3.461^{* * *}$ & 0.373 \\
\hline COMPENSATION & $0.082 * * *$ & 0.013 & $-0.137^{* * *}$ & 0.014 \\
\hline \multicolumn{5}{|l|}{ Interaction } \\
\hline AGE*NP & -0.037 & 0.023 & $-0.036^{* * *}$ & 0.006 \\
\hline AGE*ECOTOURISM & 0.000 & 0.001 & $-0.003^{* * *}$ & 0.000 \\
\hline AGE*YEAR & -0.005 & 0.005 & $0.000^{* * *}$ & 0.000 \\
\hline AGE*JOB & $0.297^{* * *}$ & 0.043 & $0.017^{* * *}$ & 0.006 \\
\hline AGE*COMPENSATION & $0.099 * * *$ & 0.026 & 0.000 & 0.004 \\
\hline EDU*NP & $0.007^{*}$ & 0.004 & $-0.009 * * *$ & 0.003 \\
\hline EDU*ECOTOURISM & $0.860 * * *$ & 0.108 & $0.344^{* * *}$ & 0.049 \\
\hline EDU*YEAR & $-0.210 * * *$ & 0.067 & $0.280 * * *$ & 0.050 \\
\hline EDU*JOB & 0.004 & 0.003 & $0.006^{* * *}$ & 0.002 \\
\hline EDU*COMPENSATION & -0.008 & 0.060 & -0.030 & 0.035 \\
\hline VILLAGE*NP & 0.348 & 0.680 & 0.170 & 0.669 \\
\hline VILLAGE*ECOTOURISM & $6.626^{* * *}$ & 1.494 & $9.766^{* * *}$ & 1.485 \\
\hline VILLAGE*YEAR & 0.022 & 0.047 & $-0.282 * * *$ & 0.063 \\
\hline VILLAGE*JOB & $3.446^{* * *}$ & 0.756 & $-4.273^{* * *}$ & 1.512 \\
\hline VILLAGE*COMPENSATION & $0.082 * *$ & 0.036 & $-0.266^{* * *}$ & 0.060 \\
\hline $\mathrm{PA}^{*} \mathrm{NP}$ & $1.088^{* *}$ & 0.498 & $-2.330^{* * *}$ & 0.526 \\
\hline PA*ECOTOURISM & $2.144^{* * *}$ & 0.590 & $6.828^{* * *}$ & 0.953 \\
\hline PA*YEAR & -0.008 & 0.028 & $-0.069 * *$ & 0.027 \\
\hline $\mathrm{PA} * \mathrm{JOB}$ & $1.497^{* * *}$ & 0.543 & $1.409^{* * *}$ & 0.442 \\
\hline PA*COMPENSATION & -0.016 & 0.021 & $0.059 * * *$ & 0.014 \\
\hline FORESTLAND*NP & 0.035 & 0.199 & $0.600^{* * *}$ & 0.131 \\
\hline FORESTLAND*ECOTOURISM & $0.558^{* *}$ & 0.250 & $2.192 * * *$ & 0.229 \\
\hline FORESTLAND*YEAR & $-0.043^{* * *}$ & 0.010 & -0.001 & 0.004 \\
\hline FORESTLAND*JOB & 0.257 & 0.207 & $2.140 * * *$ & 0.251 \\
\hline FORESTLAND*COMPENSATION & $0.055^{* * *}$ & 0.014 & $0.020 * * *$ & 0.008 \\
\hline INCOME*NP & 0.157 & 0.460 & 0.203 & 0.310 \\
\hline INCOME*ECOTOURISM & $1.046^{*}$ & 0.562 & $3.038^{* * *}$ & 0.516 \\
\hline INCOME*YEAR & -0.038 & 0.026 & $0.062^{* * *}$ & 0.022 \\
\hline INCOME*JOB & -0.233 & 0.654 & $3.278^{* * *}$ & 0.443 \\
\hline INCOME*COMPENSATION & 0.028 & 0.023 & $0.117^{* * *}$ & 0.021 \\
\hline
\end{tabular}

(1) The regression result of the attribute variable is not added to the interactions, so that the marginal coefficients can be explained directly. (2) Considering the number of parameters in one regression and to reduce collinearity, the interactions are, respectively, included in the explanatory variables. (3) The sign of the estimated standard deviations is irrelevant, they should be interpreted as being positive. $(4)^{* * *}, * *$, and ${ }^{*}$ denote statistical significance at the $1 \%, 5 \%$, and $10 \%$ levels, respectively.

Based on the standard deviation coefficient, the coefficients of the five attribute variables are significant, indicating that the farmers have greater heterogeneity in their preferences of the five 
protection and development policies, further indicating that the conditional logit model is unsuitable for this study. A mixed logit model may be necessary to address the heterogeneity of farmers.

\subsection{Impact of Farmers' Socio-Economic Characteristics on Conservation and Development Policy Preference}

In the selection of social and economic characteristics, age, education level, whether the respondent is a village cadre, family forestland area, family income, and whether the respondent lives in an NR are important manifestations of the socio-economic characteristics of the affected farmers. With urbanization and the retreat of rural primary and secondary schools, most of the members of the surrounding communities in the NR that are left behind are elderly. In the future, as the education level of their children is further improved, the community aging issue will become more serious.

The regression results show that older farmers prefer to choose a combination of high ecological compensation and provision of ecological jobs. Older farmers have limited ability to participate in ecotourism, have less knowledge of the new NP, and are less willing to participate. They are more concerned about how to obtain direct economic benefits, ecological compensation and ecological jobs are policies that can bring direct income to farmers and thus, are favored by older farmers when assessing conservation and development policies.

Farmers with high education levels are more likely to participate in the establishment of NP and to develop ecotourism. Based on various information media, they can better understand that the government attaches importance to the establishment of NPs, and that this can bring a number of non-agricultural employment opportunities to the community. Moreover, they have a higher ability to participate in ecotourism management and can benefit from the ecotourism development process.

Village cadres are more inclined to choose to increase ecotourism development, increase ecological compensation, and provide ecological jobs, all of which are important driving forces for community development. Their preference for participation in the establishment of NP and compensation period is not significant. The willingness of communities inside NRs to change the conservation and development policies is strong, and there is a significant positive preference for the establishment of NPs, ecotourism development, compensation for public welfare forests, and providing ecological jobs.

Communities inside the NR are strictly restricted by the conservation policy and most NRs emphasize nature protection while neglecting community interests. Therefore, these communities expect to establish NPs. Most of the communities in the NRs are located in areas with beautiful natural landscapes and rich biodiversity and have the necessary conditions for ecotourism development. There is no obvious difference in preferences between the communities inside and outside the NRs in terms of ecological posts and compensation of ecological public welfare forests.

Farmers with large family forests are more inclined towards ecotourism development, shorter compensation periods, and higher compensation amounts, but they have no strong preference for the establishment of NPs and ecological jobs. This is because farmers with more forestland have material conditions for ecotourism. The rich forest resources are conducive to activities such as undergrowth landscape viewing, fishing, and undergrowth breeding. Moreover, they can provide abundant wild vegetables, mushrooms, fungi, and other foods. Lastly, a shorter compensation period is conducive to farmers with rich forest resources to obtain more compensation opportunities.

Farmers with high incomes prefer ecotourism development and establishment of NPs, but their preferences for other policy attributes are not significant. The reason is that farmers with high incomes are more satisfied with the current development status. While the establishment of NPs can yield more employment opportunities, it may also increase the intensity of protection and limit the scale utilization of natural resources. Even if the existing compensation for ecological public welfare forests were to increase, it would account for only a small portion of household income. In addition, farmers with higher incomes have more non-agricultural employment channels, and their demand for ecological jobs is not strong. However, their ability to participate in ecotourism development is stronger, including participation in ecotourism management and non-agricultural employment opportunities. Even if participation were impossible, ecotourism development would enhance their cultural welfare, in terms 
of better landscape views, recreation, and other forms of entertainment. Moreover, the improved infrastructure construction in the surrounding areas would improve their well-being levels.

Considering that logit regression belongs to the family of generalized linear models and its expression ability is limited, in the process of mixed logit regression, this study discretizes the family forestland area and per capita net income, which can simplify the model and reduce the risk of model over-fitting. It is also easy to quickly iterate the model and improve its predictive ability.

\subsection{Farmers' Preference for Conservation and Development Policies}

Farmers have different preferences for different conservation and development policies. Understanding their degree of preference for different policies plays an important role in the latter's implementation. Formula (11) is used to calculate the preference of farmers based on the estimated coefficients of different policy attributes in Table 4 as shown below.

Table 4. Farmers' preferences for different policy attributes.

\begin{tabular}{ccc}
\hline Attribute & Coefficient & Preference \\
\hline NP & 0.314 & -3.825 \\
ECOUTOURISM & 1.540 & -18.780 \\
YEAR & 0.020 & -0.239 \\
COMPENSATION & 0.082 & \\
JOB & 1.218 & -14.836 \\
\hline
\end{tabular}

The results in Table 4 indicate that there is a large difference in the farmers' degree of preference for different conservation and development policies. Farmers have the highest preference for ecotourism development policies and are willing to forego $18.8 \mathrm{yuan} / \mathrm{mu}$ in compensation for ecological public welfare forests if the government increases the development of scenic spots.

This figure exceeds the compensation of the current national-level ecological public welfare forest. On the one hand, this indicates that the current compensation for national-level public welfare forests is low while, on the other hand, the communities have a high demand for, and are willing to pay towards, ecotourism development. Farmers' preferences for ecological jobs ranks second, and farmers are willing to reduce the amount of ecological public welfare forest compensation by $14.8 \mathrm{yuan} / \mathrm{mu}$ in exchange. This is, basically, consistent with the national ecological public welfare forest compensation standards. The communities' preference for the establishment of NPs ranks third. Farmers are positive towards the establishment of NPs and are willing to forego compensation of 3.8 yuan/mu/year in exchange. The communities have a lower preference for the compensation period of ecological public welfare forests. For each additional year of compensation, farmers are willing to reduce the compensation amount of the ecological public welfare forest by 0.24 yuan $/ \mathrm{mu}$.

On the one hand, the positive effects of conservation and development policies on community participation in conservation have been explained by existing research, which found that ecotourism participation, ecological compensation, and other conservation mechanisms generate livelihoods for the community $[9,18,23,28]$. On the other hand, several studies found that PAs have actually caused a negative effect on livelihood. This is in line with the results of our study, suggesting that the establishment of PAs should be combined with conservation and development policies which take into account local preferences and increase community participation [13-17].

\section{Conclusions}

Based on the heterogeneity hypothesis of farmers, this study designed the experimental program by selecting a combination of conservation and development policies and using a mixed logit model to measure the farmers' participation and preferences for different policies in the Qinling NRs. The main findings are as follows. 
First, the establishment of NPs, ecotourism development, compensation period, ecological posts, and compensation for ecological public welfare forests can significantly increase farmers' willingness to participate in ecological conservation programs. Second, farmers have different preferences for different conservation and development policies. They have the highest preference for ecotourism development, followed by ecological jobs, establishment of NPs, and finally, the compensation amount and period for the ecological public welfare forest. Third, there are significant differences in the degree of preference for conservation and development policies among farmers with different socio-economic characteristics. Older farmers prefer a combination of high ecological compensation and the provision of ecological jobs. Farmers with higher education levels prefer to participate in the establishment of NPs and ecotourism development. Village cadres are more inclined towards increasing ecotourism development, improving ecological compensation, and providing ecological jobs. Communities living inside NRs have a strong willingness to change the current status of conservation and development policies and have significant positive preferences for the establishment of NPs, ecotourism development, compensation for public welfare forests, and the provision of ecological jobs. Households with large family forestlands are more inclined to ecotourism development, shorter compensation periods, and higher compensation amounts. Farmers with higher incomes prefer ecotourism development. our study confirms the importance of combined conservation and development policies to promote community participation in conservation. Moreover, our study analyzes the relationship between different conservation and development policies from the perspective of the community.

The conclusions of this study have important implications for the improvement of conservation and development policies. First, there is a one-size-fits-all phenomenon in current protection and development policies, which does not take into account the linkages and synergies between different policies. Conservation and development policies should complement each other and work together to achieve coordination. For example, in some giant panda NRs without ecotourism development, the establishment of NRs have increased poverty and caused income losses due to wildlife crop destruction and insufficient compensation from ecological projects. However, in NRs with more developed ecotourism and higher ecological compensation, community seem to have suffered less conservation costs and benefited more form conservation activities.

Second, although the communities' highest preference is for ecotourism development, this reflects the farmers' high expectations, which are often difficult to meet in reality. Greater consideration should be given to how to make the community participate in the benefits. When ecotourism development cannot achieve sustainable livelihood improvements for a community and only a small number of people benefit, the gap between the rich and the poor will increase. Moreover, the development of ecotourism will inevitably have a negative impact on the protection of species and their habitats. Therefore, the development benefits of ecotourism need to be returned for biodiversity conservation and community development, in particular through the forest guard posts. In areas where ecotourism has not been developed, it is necessary to increase government transfer payments to improve community infrastructure and ecological compensation.

Third, the degree of benefit from different conservation and development policies differs by community. Only a small number of people have obtained the benefits of ecotourism and ecological jobs. While most people cannot participate, the communities still have the strongest preference for these two policies. Although the coverage of ecological public welfare forests is large, most farmers can participate in the benefits. However, the communities' benefits are insufficient and the funding sources are unstable, which cannot serve as a sustainable income source for households. To this end, the government should broaden the funding sources in the implementation of conservation and development policies and undertake measures to increase the participation of rural labor.

Although this study explored community participation and preferences with respect to different conservation and development policies, the social and ecological effects of these policies, as well as their interaction effects, were not fully captured. Future studies could perform social and ecological impact evaluation about conservation and development policies. 
Author Contributions: Conceptualization, B.M. and Y.W.; methodology, B.M.; software, B.M.; formal analysis, B.M.; investigation, B.M. and Y.W.; data curation, Y.W.; writing-original draft preparation, B.M.; writing-review and editing, Y.W.; project administration, Y.W.; funding acquisition, Y.W.

Funding: This research was funded by the NATURAL SCIENCE FOUNDATION OF CHINA, grant numbers 71861147001 and 71373024 and the CHINA SCHOLARSHIP COUNCIL.

Acknowledgments: We would also like to express our gratitude to the anonymous reviewers. We are grateful to Runsheng Yin from Michigan State University for the constructive suggestions and Yuan Huang from Beijing Forestry university for helping with the cartography. Any remaining errors are solely our own.

Conflicts of Interest: The authors declare no conflict of interest.

\section{Appendix A}

Table A1. Example of a stated preference choice experiment included in the survey.

\begin{tabular}{|c|c|c|c|}
\hline Properties & Choice A & Choice B & Choice C \\
\hline NP & Establishment of NP & Maintain status quo & \multirow{5}{*}{$\begin{array}{l}\text { I'm not going to choose } \\
\text { either one }\end{array}$} \\
\hline Ecotourism & $\begin{array}{l}\text { Increase the development of } \\
\text { scenic spots }\end{array}$ & Maintain status quo & \\
\hline $\begin{array}{l}\text { Compensation period of } \\
\text { ecological welfare forests }\end{array}$ & 1 year & 15 years & \\
\hline Ecological jobs & None & Provide ecological jobs & \\
\hline $\begin{array}{c}\text { Compensation of } \\
\text { ecological welfare forests }\end{array}$ & 0 yuan/mu/year & 21-30 yuan/mu/year & \\
\hline Your choice & & & \\
\hline
\end{tabular}

\section{References}

1. Pimbert, M.P.; Pretty, J.N. Parks, people and professionals: Putting 'participation' into protected-area management. In Social Change and Conservation, 1st ed.; Ghimire, K.B., Pimbert, M.P., Eds.; Earthscan: London, UK, 1997; Volume 16, pp. 297-330.

2. Wright, G.D.; Andersson, K.P.; Gibson, C.C.; Evans, T.P. Decentralization can help reduce deforestation when user groups engage with local government. Proc. Natl. Acad. Sci. USA 2016, 113, 14958-14963. [CrossRef]

3. da Silva, M.X.; Paviolo, A.; Tambosi, L.R.; Pardini, R. Effectiveness of Protected Areas for biodiversity conservation: Mammal occupancy patterns in the Iguaçu National Park, Brazil. J. Nat. Conserv. 2018, 41, 51-62. [CrossRef]

4. Su, X.; Han, W.; Liu, G.; Zhang, Y.; Lu, H. Substantial gaps between the protection of biodiversity hotspots in alpine grasslands and the effectiveness of protected areas on the Qinghai-Tibetan Plateau, China. Agric. Ecosyst. Environ. 2019, 278, 15-23. [CrossRef]

5. Palmer, C.; Di Falco, S. Biodiversity, poverty, and development. Oxf. Rev. Econ. Policy 2012, 28, 48-68. [CrossRef]

6. Leite, A.; Cáceres, A.; Melo, M.; Mills, M.S.; Monteiro, A.T. Reducing emissions from Deforestation and forest Degradation in Angola: Insights from the scarp forest conservation 'hotspot'. Land Degrad. Dev. 2018, 29, 4291-4300. [CrossRef]

7. Liu, J.; Miao, H.; Zheng, H. Analysis on modes of harmonious development of nature reserve and local community in Wolong nature reserve. Acta Ecol. Sin. 2009, 29, 260-268.

8. Wang, C.; Wen, Y.; Hu, C.; Si, K. Research progress on harmonious development of NRs and surrounding communities. Issues For. Econ. 2010, 30, 486-492.

9. Liu, J.; Hull, V.; Yang, W.; Viña, A.; Chen, X.; Ouyang, Z.; Zhang, H. Pandas and People: Coupling Human and Natural Systems for Sustainability; Oxford University Press: Oxford, UK, 2016.

10. Ferraro, P.J.; Hanauer, M.M. Through what mechanisms do protected areas affect environmental and social outcomes? Philos. Trans. R. Soc. B Biol. Sci. 2015, 370, 20140267. [CrossRef]

11. Miranda, J.J.; Corral, L.; Blackman, A.; Asner, G.; Lima, E. Effects of protected areas on forest cover change and local communities: Evidence from the Peruvian Amazon. World Dev. 2016, 78, 288-307. [CrossRef] 
12. Clements, T.; Suon, S.; Wilkie, D.S.; Milner-Gulland, E.J. Impacts of protected areas on local livelihoods in Cambodia. World Dev. 2014, 64, S125-S134. [CrossRef]

13. Cernea, M.M.; Schmidt-Soltau, K. Poverty risks and national parks: Policy issues in conservation and resettlement. World Dev. 2006, 34, 1808-1830. [CrossRef]

14. Coad, L.; Campbell, A.; Miles, L.; Humphries, K. The Costs and Benefits of Forest Protected Areas for Local Livelihoods: A Review of the Current Literature (Working Paper); UNEP World Conservation Monitoring Centre: Cambridge, UK, 2008.

15. Duan, W.; Wen, Y. Impacts of protected areas on local livelihoods: Evidence of giant panda biosphere reserves in Sichuan Province, China. Land Use Policy 2017, 68, 168-178. [CrossRef]

16. Ferraro, P.J. The local costs of establishing protected areas in low-income nations: Ranomafana National Park, Madagascar. Ecol. Econ. 2002, 43, 261-275. [CrossRef]

17. De Sherbinin, A. Is poverty more acute near parks? An assessment of infant mortality rates around protected areas in developing countries. Oryx 2008, 42, 26-35. [CrossRef]

18. Andam, K.S.; Ferraro, P.J.; Sims, K.R.E.; Healy, A.; Holland, M.B. Protected areas reduced poverty in Costa Rica and Thailand. Proc. Natl. Acad. Sci. USA 2010, 107, 9996-10001. [CrossRef]

19. Roe, D.; Mohammed, E.Y.; Porras, I.; Giuliani, A. Linking biodiversity conservation and poverty reduction: De-polarizing the conservation-poverty debate. Conserv. Lett. 2013, 6, 162-171. [CrossRef]

20. Liu, C.; Li, J.; Pechacek, P. Current trends of ecotourism in China's nature reserves: A review of the Chinese literature. Tour. Manag. Perspect. 2013, 7, 16-24. [CrossRef]

21. Demir, S.; Esbah, H.; Akgün, A.A. Quantitative SWOT analysis for prioritizing ecotourism-planning decisions in protected areas: Igneada case. Int. J. Sustain. Dev. World Ecol. 2016, 23, 456-468. [CrossRef]

22. Mossaz, A.; Buckley, R.C.; Castley, J.G. Ecotourism contributions to conservation of African big cats. J. Nat. Conserv. 2015, 28, 112-118. [CrossRef]

23. Ferraro, P.J.; Hanauer, M.M. Quantifying causal mechanisms to determine how protected areas affect poverty through changes in ecosystem services and infrastructure. Proc. Natl. Acad. Sci. USA 2014, 111, 4332-4337. [CrossRef]

24. Coria, J.; Calfucura, E. Ecotourism and the development of indigenous communities: The good, the bad, and the ugly. Ecol. Econ. 2012, 73, 47-55. [CrossRef]

25. Buckley, R. Protecting lemurs: Ecotourism. Science 2014, 344, 358. [CrossRef]

26. Das, M.; Chatterjee, B. Ecotourism: A panacea or a predicament? Tour. Manag. Perspect. 2015, 14, 3-16. [CrossRef]

27. Zhong, L.; Liu, L. Ecotourism development in China: Achievements, problems and strategies. J. Resour. Ecol. 2017, 8, 441-448. [CrossRef]

28. Lonn, P.; Mizoue, N.; Ota, T.; Kajisa, T.; Yoshida, S. Evaluating the contribution of community-based ecotourism (CBET) to household income and livelihood changes: A case study of the Chambok CBET program in Cambodia. Ecol. Econ. 2018, 151, 62-69. [CrossRef]

29. Ma, B.; Cai, Z.; Zheng, J.; Wen, Y. Conservation, ecotourism, poverty, and income inequality-A case study of nature reserves in Qinling, China. World Dev. 2019, 115, 236-244. [CrossRef]

30. Ezzine-de-Blas, D.; Wunder, S.; Ruiz-Pérez, M.; del Pilar Moreno-Sanchez, R. Global patterns in the implementation of payments for environmental services. PLoS ONE 2016, 11, e0149847. [CrossRef]

31. Chervier, C.; Le Velly, G.; Ezzine-de-Blas, D. When the implementation of payments for biodiversity conservation leads to motivation crowding-out: A case study from the Cardamoms Forests, Cambodia. Ecol. Econ. 2019, 156, 499-510. [CrossRef]

32. Liu, J.; Viña, A.; Yang, W.; Li, S.; Xu, W.; Zheng, H. China's environment on a metacoupled planet. Annu. Rev. Environ. Resour. 2018, 43, 1-34. [CrossRef]

33. Shi, M.; Qi, J.; Yin, R. Has China's natural forest protection program protected forests?-Heilongjiang's Experience. Forests 2016, 7, 218. [CrossRef]

34. Yin, R. An Integrated Assessment of China's Ecological Restoration Programs; Springer: Dordrecht, The Netherlands, 2009.

35. Börner, J.; Baylis, K.; Corbera, E.; Ezzine-de-Blas, D.; Honey-Rosés, J.; Persson, U.M.; Wunder, S. The effectiveness of payments for environmental services. World Dev. 2017, 96, 359-374. [CrossRef] 
36. Liu, J.; Diamond, J. Revolutionizing China's environmental protection. Science 2008, 319, 37-38. [CrossRef]

37. Wang, J.H.Z. National parks in China: Parks for people or for the nation? Land Use Policy 2019, 81, 825-833. [CrossRef]

38. National Development and Reform Commission. National Development and Reform Commission Q\&A on the Overall Plan for Establishing a National Park System. 2017. Available online: http://www.gov.cn/ zhengce/2017-09/27/content_5227895.htm (accessed on 5 March 2019).

39. Pienaar, E.F.; Jarvis, L.S.; Larson, D.M. Using a choice experiment framework to value conservation-contingent development programs: An application to Botswana. Ecol. Econ. 2014, 98, 39-48. [CrossRef]

40. Lee, D.E.; Du Preez, M. Determining visitor preferences for rhinoceros conservation management at private, ecotourism game reserves in the Eastern Cape Province, South Africa: A choice modeling experiment. Ecol. Econ. 2016, 130, 106-116. [CrossRef]

41. Adamowicz, W.; Boxall, P.; Williams, M.; Louviere, J. Stated preference approaches for measuring passive use values: Choice experiments and contingent valuation. Am. J. Agric. Econ. 1998, 80, 64-75. [CrossRef]

42. Allenby, G.M.; Rossi, P.E. Marketing models of consumer heterogeneity. J. Econ. 1998, 89, 57-78. [CrossRef]

43. Cook, R.D.; Nachtrheim, C.J. A comparison of algorithms for constructing exact D-optimal designs. Technometrics 1980, 22, 315-324. [CrossRef]

44. Zwerina, K.; Huber, J.; Kuhfeld, W.F. A General Method for Constructing Efficient Choice Designs; Fuqua School of Business, Duke University: Durham, NC, USA, 1996.

45. Carlsson, F.; Martinsson, P. Design techniques for stated preference methods in health economics. Health Econ. 2003, 12, 281-294. [CrossRef]

46. Zhou, L. Qinling Giant Panda: The Fourth Panda Survey in Shaanxi Province; Shaanxi Science and Technology Press: Xi'an, China, 2017; pp. 18-20.

47. The State Council Leading Group Office of Poverty Alleviation and Development. List of Key Counties for National Poverty Alleviation and Development Work. 2012. Available online: http://www.cpad.gov.cn/art/ 2012/3/19/art_343_42.html (accessed on 7 July 2019).

48. Ministry of Environmental Protection of the People's Republic of China. National Nature Reserve directory. 2016. Available online: http://sts.mee.gov.cn/zrbhdjg/201905/P020190514616066259275.pdf (accessed on 30 May 2019).

49. Hall, J.; Viney, R.; Haas, M.; Louviere, J. Using stated preference discrete choice modeling to evaluate health care programs. J. Bus. Res. 2004, 57, 1026-1032. [CrossRef]

50. Lancaster, K.J. A new approach to consumer theory. J. Political Econ. 1966, 74, 132-157. [CrossRef]

51. McFadden, D.L. Conditional logit analysis of qualitative choice behavior. In Frontiers in Econometrics; Zarembka, P., Ed.; Academic Press: New York, NY, USA, 1974; pp. 105-142.

52. Wu, L.H.; Wang, S.X.; Hu, W. Consumer preferences and willingness to pay for traceable food attributes: Case of pork. Chin. Rural Econ. 2014, 8, 58-75.

53. Lybbert, T.J.; Magnan, N.; Bhargava, A.K.; Gulati, K.; Spielman, D.J. Farmers' heterogeneous valuation of laser land leveling in eastern Uttar Pradesh: An experimental auction to inform segmentation and subsidy strategies. Am. J. Agric. Econ. 2012, 95, 339-345. [CrossRef]

54. Verhofstadt, E.; Maertens, M. Can agricultural cooperatives reduce Poverty? Heterogeneous impact of cooperative membership on farmers' welfare in Rwanda. Appl. Econ. Perspect. Policy 2015, 37, 86-106. [CrossRef]

55. McFadden, D.; Train, K. Mixed MNL models for discrete response. J. Appl. Econ. 2000, 15, 447-470. [CrossRef]

56. Brownstone, D.; Train, K. Forecasting new product penetration with flexible substitution patterns. J. Econ. 1998, 89, 109-129. [CrossRef]

57. Hole, A.R. Fitting mixed logit models by using maximum simulated likelihood. Stata J. 2007, 7, 388-401. [CrossRef]

58. Morrison, M.; Bennett, J.; Blamey, R.; Louviere, J. Choice modeling and tests of benefit transfer. Am. J. Agric. Econ. 2002, 84, 161-170. [CrossRef] 
59. Ma, B.; Lei, S.; Qing, Q.; Wen, Y. Should the Endangered Status of the Giant Panda Really Be Reduced? The Case of Giant Panda Conservation in Sichuan, China. Animals 2018, 8, 69. [CrossRef]

60. Ma, B.; Zhao, Z.; Ding, H.; Wen, Y. Household costs and benefits of biodiversity conservation: Case study of Sichuan giant panda reserves in China. Environ. Dev. Sustain. 2018, 20, 1665-1686. [CrossRef]

(C) 2019 by the authors. Licensee MDPI, Basel, Switzerland. This article is an open access article distributed under the terms and conditions of the Creative Commons Attribution (CC BY) license (http://creativecommons.org/licenses/by/4.0/). 